\title{
Micromechanical Modeling of High-Strain Thin-Ply Composites
}

\author{
Milinda Yapa Hamillage* and Kawai Kwok ${ }^{\dagger}$ \\ University of Central Florida, Orlando, FL 32816 \\ Juan M. Fernandez \\ NASA Langley Research Center, Hampton, VA 32681
}

\begin{abstract}
This paper presents a micromechanical analysis for the elastic and viscoelastic behavior of high-strain thin-ply composites. The modeling approach is based on unit cell homogenization. The geometry of the internal weave architecture and ply configuration is characterized via micrographic analysis and explicitly modeled in the unit cell. The composites are modeled as Kirchhoff plates and the homogenization analysis computes the effective relaxation ABD matrix represented by Prony series using the elastic and viscoelastic properties of the constituent fiber and matrix. The formulation of the micromechanical model and numerical implementation are presented. Composite laminates with 3-ply and 4-ply configurations are studied.
\end{abstract}

\section{Nomenclature}

$\begin{array}{ll}A B D & \text { relaxation ABD matrix } \\ a_{T} & \text { shift factor } \\ C & \text { relaxation modulus tensor } \\ N & \text { force resultant } \\ T & \text { temperature } \\ T_{0} & \text { reference temperature } \\ \varepsilon & \text { strain } \\ \kappa & \text { curvature } \\ \rho & \text { relaxation time } \\ \sigma & \text { stress }\end{array}$

\section{Introduction}

With the demand for high performance light weight structural materials in the aerospace industry, thin-ply composites have gained interest in the aerospace structures community due to various design capabilities that are proper from them. Thin-ply composites are composed of thin spread-tows manufactured from large tows that undergo a careful spreading process. These processes allow to reduce the thickness of the tows up to six fold [1] producing composites much thinner than the conventional composites.

The capability of manufacturing thin-ply composites allows more plies to be used at different orientations for the same thickness of their conventional counterparts and achieve improved mechanical performance [2]. These thin fiber composites can be used for space applications in thin deployable reflector concepts [3] as carbon fiber reinforced sheets [4, 5] and structures consisting of tape spring elements. The applications for these structural elements include ultra-thin deployable booms [6, 7] for solar sails [8], stiff and lightweight truss elements in space structures. The aforementioned structures deploy into a volume larger than a standard payload shroud requiring storage in a smaller space for transportation. For example, in new deployable reflector concept [3], the carbon fiber reinforced plastic sheets in the structure are folded to obtain a configuration required for transportation.

The space structures of this nature are self-deployed by the strain energy stored in the system when folding. The composites are made from polymer matrix and carbon fiber. The matrix is a polymer resin with inherent viscoelastic behavior and this causes problems of reduction in the strain energy stored in the composites over time, hindering

\footnotetext{
*Graduate Student, Department of Mechanical and Aerospace Engineering, 12760 Pegasus Blvd.

$\dagger$ Assistant Professor, Department of Mechanical and Aerospace Engineering, 12760 Pegasus Blvd., P.O. Box 162450, AIAA Member.

${ }^{\dagger}$ Research Aerospace Engineer, Structural Dynamics Branch, NASA LaRc, 4 West Taylor Street, Mail Stop 230, AIAA Member
} 
the self-deployment. Since the composites are subjected to high strains and bent to high curvatures, the mechanical properties of these composites are crucial to assessing how the structure will behave during and after deployment. The classical laminate theory can accurately predict the in-plane properties of fiber composites but over-predict the bending properties by 200\%-400\% [9]. There have been developments in research in testing to assess the elastic [1] and viscoelastic [10] behavior of high-strain thin-ply composites. Testing cannot provide a thorough understanding of the mechanical behavior due to difficulty in acquiring coupling effects inherent in composites, therefore numerical modeling has been a successful passage over the years to fully assess both elastic and viscoelastic behavior of composites. Although the elastic and viscoelastic behavior of conventional composites have been studied [11, 12] through numerical models, the knowledge on behavior of high-strain thin-ply composites is limited.

This study focuses on micromechanical models for predicting the elastic and viscoelastic properties of thin-ply composites. Micrographs are studied to extract the geometric parameters of the woven thin-ply laminates. Two homogenized models of two scales are used in the study to determine the mechanical properties of the laminates. The first model is used to assess the mechanical properties of a unidirectional tow and the mechanical properties acquired from this model are used in the second model to assess the laminates in both elastic and viscoelastic behaviors. For the elastic analysis the ABD matrix is formulated and bending behavior is studied for high curvatures, whereas viscoelastic behavior is characterized in the form of an $\mathrm{ABD}$ relaxation matrix and is formulated for two different orientations of the laminate.

\section{Viscoelastic Plate Model}

We first introduce a viscoelastic plate model [12] describing the mechanical constitutive response of thin-ply composites. The time and temperature dependent behavior of the composite is modeled with linear viscoelasticity theory. The three-dimensional stress-strain relation of a continuum is expressed by the Boltzmann superposition integral:

$$
\sigma_{i}(t)=\int_{0}^{t} C_{i j}(t-\tau) \frac{d \epsilon_{j}}{d \tau} d \tau
$$

where $\sigma$ and $\epsilon$ are stress and strain ordered according to the Voigt notation, $\mathrm{t}$ is time, and $C$ is the 6-by-6 relaxation modulus tensor. The number of independent entries depend on the material symmetry in the same way as in elasticity theory. All the entries in the relaxation modulus tensor are functions of time and temperature represented by Prony series defined by

$$
C_{i j}=C_{i j, \infty}+\sum_{k=1}^{n} C_{i j, k} \exp \left(\frac{-t}{a_{T} \rho_{k}}\right)
$$

where $C_{i j, \infty}$ are the long-term moduli, $C_{i j, k}$ are the Prony coefficients, $\rho_{k}$ are the relaxation times at the reference temperature $T_{0}$, and $a_{T}$ is the temperature shift factor. In this formulation, the relaxation times are not dependent on material symmetry and all entries in the modulus tensor have the same set of relaxation times.

The temperature dependence is included in the constitutive equations through the temperature shift factor $a_{T}$ that is based on the time-temperature superposition principle. The shift factor is defined as

$$
a_{T}=\frac{\rho(T)}{\rho\left(T_{0}\right)}
$$

The material is described as thermorheologically simple if the same shift factor applies to all relaxation times. This is the behavior assumed in this paper. The viscoelastic plate model is constructed by applying the Kirchhoff assumptions that present the strain field as:

$$
\begin{gathered}
\epsilon_{1}=\bar{\epsilon}_{1}, \quad \epsilon_{2}=\bar{\epsilon}_{2}+x_{3} \bar{\kappa}_{2}, \quad \epsilon_{6}=\bar{\epsilon}_{3}+x_{3} \bar{\kappa}_{3} \\
\epsilon_{3}=\epsilon_{4}=\epsilon_{5}=0
\end{gathered}
$$

where $\bar{\epsilon}$ and $\bar{\kappa}$ are the in-plane strains and the curvatures of the plate reference plane. The force and moment resultants, $\bar{N}$ and $\bar{M}$, are obtained by integrating the stresses over the plate thickness $\mathrm{h}$,

$$
\bar{N}_{1}=\int_{h} \sigma_{1} d x_{3}, \quad \bar{N}_{2}=\int_{h} \sigma_{2} d x_{3}, \quad \bar{N}_{3}=\int_{h} \sigma_{6} d x_{3}
$$




$$
\bar{M}_{1}=\int_{h} x_{3} \sigma_{1} d x_{3}, \quad \bar{M}_{2}=\int_{h} x_{3} \sigma_{2} d x_{3}, \quad \bar{M}_{3}=\int_{h} x_{3} \sigma_{6} d x_{3}
$$

Substituting the 3D strains into the 3D constitutive equations presented in Eq. (1) and then into the force and moment resultants completes the viscoelastic plate model,

$$
\begin{aligned}
& \bar{N}_{i}(t)=\int_{0}^{t} A_{i j}(t-\tau) \frac{d \bar{\epsilon}_{j}(\tau)}{d \tau} d \tau+\int_{0}^{t} B_{i j}(t-\tau) \frac{d \bar{\kappa}_{j}(\tau)}{d \tau} d \tau \\
& \bar{M}_{i}(t)=\int_{0}^{t} B_{i j}(t-\tau) \frac{d \bar{\epsilon}_{j}(\tau)}{d \tau} d \tau+\int_{0}^{t} D_{i j}(t-\tau) \frac{d \bar{\kappa}_{j}(\tau)}{d \tau} d \tau
\end{aligned}
$$

where $A, B$, and $D$ are the extensional relaxation stiffness, extension-bending coupling relaxation stiffness, and bending relaxation stiffness matrix respectively as defined by a Kirchhoff plate. They each have a dimension of 3-by-3. Each entry of the ABD matrix is represented by a Prony series, and is dependent on the viscoelastic properties of the fiber and matrix, the weave geometry, and the layup. The Prony series representation is given by

$$
\begin{aligned}
& A_{i j}=A_{i j, \infty}+\sum_{k=1}^{n} A_{i j, k} \exp -\left(\frac{t}{\rho_{k}}\right) \\
& B_{i j}=A_{i j, \infty}+\sum_{k=1}^{n} B_{i j, k} \exp -\left(\frac{t}{\rho_{k}}\right) \\
& D_{i j}=D_{i j, \infty}+\sum_{k=1}^{n} D_{i j, k} \exp -\left(\frac{t}{\rho_{k}}\right)
\end{aligned}
$$

\section{Material Properties}

Layups made of three and four plies are investigated in this study. All composite coupons are fabricated with M30S carbon fiber and PMT-F7 epoxy resin. The longitudinal stiffness $E_{1}$ of the fibers was obtained from Toray Industries [13]. The other values were estimated by using $E_{1}$ and data in literature [11]. The values acquired and calculated are given in Table1. The M30S fibers have a diameter of $5.5 \mu \mathrm{m}$.

Table 1 Material Properties of M30S.

\begin{tabular}{lc}
\hline \hline Properties & M30S Fiber \\
\hline Longitudinal Stiffness, $E_{1}(\mathrm{MPa})$ & 294,000 \\
Transverse Stiffness, $E_{2}(\mathrm{MPa})$ & 29148 \\
Shear Stiffness, $G_{12}(\mathrm{MPa})$ & 11310 \\
In-plane Shear Stiffness, $G_{23}(\mathrm{MPa})$ & 10000 \\
Poisson's Ratio, $v_{12}=v_{13}$ & 0.2 \\
Poisson's Ratio, $v_{23}$ & 0.46 \\
\hline
\end{tabular}

The epoxy matrix is regarded as an isotropic viscoelastic material pertaining to the material model as demonstrated in Section II] The relaxation modulus for the epoxy at $30^{\circ} \mathrm{C}$ was acquired from literature [14] and plotted in Fig. 11. The epoxy was assumed to have a constant Poisson's ratio of 0.36 . 


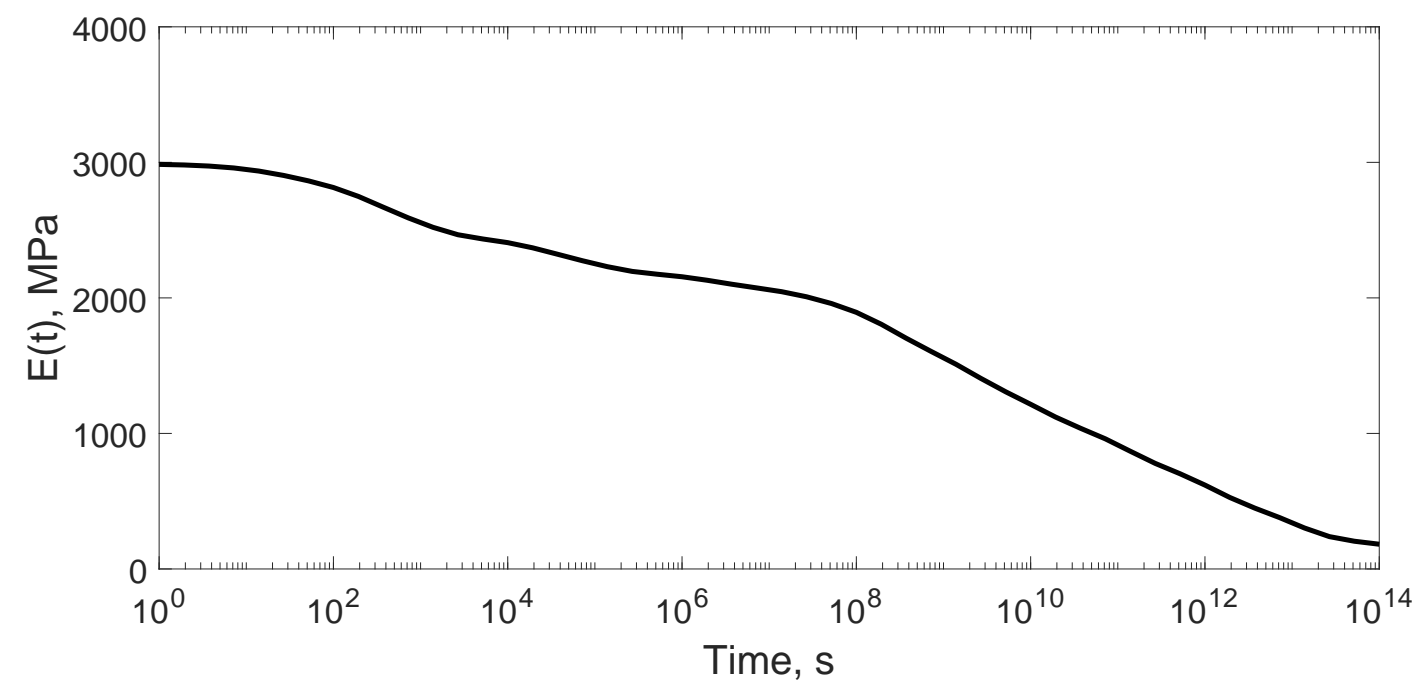

Fig. 1 Uniaxial relaxation modulus of PMT-F7 epoxy at $30^{\circ} \mathrm{C}$.

\section{Micromechanical Models}

This section describes the approach and implementation of a numerical model to assess the viscoelastic behavior of thin-ply laminates. Key geometric properties are obtained from micrographs to create the unit cell geometry which is followed by a two-step homogenization technique [12] to formulate the numerical model. The unit cell is selected such that it remains a representative volume element when the entire composite is considered. The analyses were carried out on two different orientations of the laminates as given in Fig. 2. Namely $45^{\circ}$ and $0^{\circ}$. The thin-ply laminates studied in this paper are potential material constituents for the thin-shell composite boom concepts in the Advanced Composite-Based Solar Sail System (ACS3) [8] developed at NASA Langley Research Center.

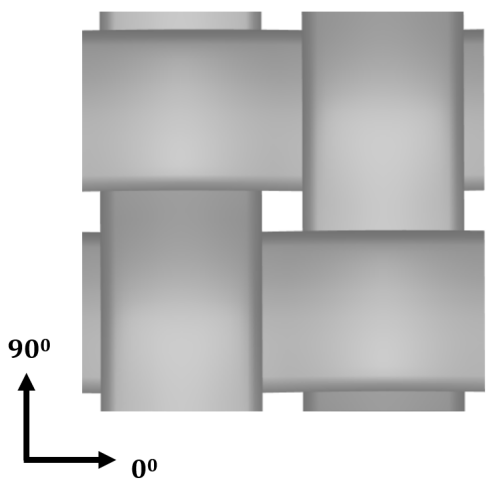

(a)

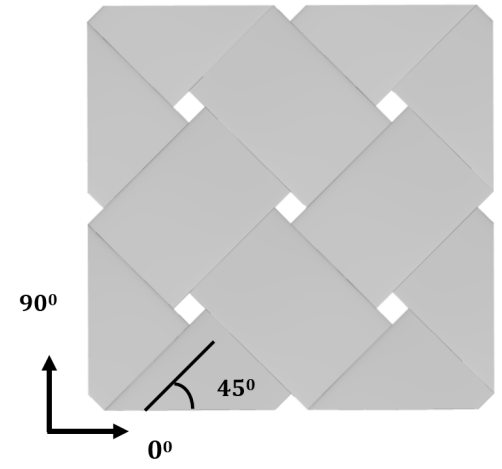

(b)

Fig. 2 Laminate orientations: a) $0^{\circ}$ orientation of laminate, and b) $45^{\circ}$ orientation of laminate.

\section{A. Unit Cell Geometry}

The composites studied in the paper are fabricated laying up three and four plies of plain weave lamina. By translating plies on one-another, an infinite number of ply arrangements can be obtained for any composite with two or more plies. Here the mechanical properties of composites with plies in-phase configuration are studied which takes a form as in Fig. 3 


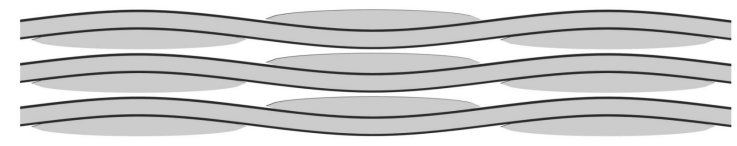

(a)

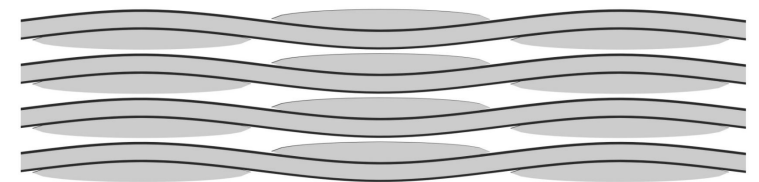

(b)

Fig. 3 In phase configurations: a) 3-ply plain weave laminate, and b) 4-ply plain weave laminate.

The geometric parameters required to define the unit cell are the tow cross-sectional shape, tow area and tow weave geometry. A typical micrograph of the 4-ply composite is shown in Fig. 4 . The determination of geometric properties was carried out by using the ImageJ software [15]. The width $w$ of the tows was obtained by measuring a carefully drawn horizontal line across the width of the tow. Tow spacing $s$ was measured following a similar methodology and this was incorporated with the tow width to calculate the weave length $l$ given by

$$
l=2(w+s)
$$

The laminate thickness was obtained by measuring a vertical line drawn across the laminate and an eighth of this value was considered as the tow thickness after confirming that this value agrees with the measurements of individual tows. The area of a polygon traced around the tow was measured to be the tow area.

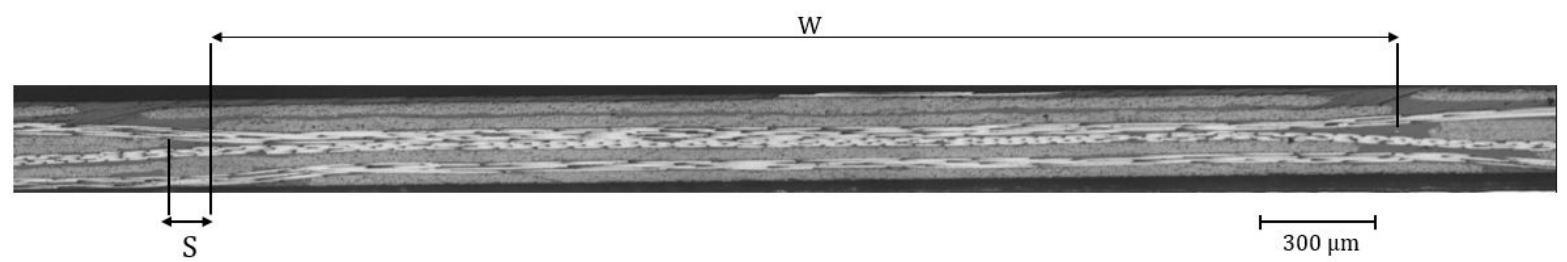

Fig. 4 Micrograph of M30S/PMT-F7 Composite.

Another critical parameter is the fiber volume fraction of the tows. Several micrographs were used in the format as in Fig. 5 with an area of interest bounded by a rectangle. The area of one fiber was multiplied by the number of fibers in the area of interest to calculate the area fraction of fibers which is identical to the tow fiber volume fraction. Since there is resin residing surrounding the woven tows, the volume fraction of fiber in the laminate is different. This was done by first measuring the curved length of the fibers along a weave length to calculate the volume of the tows in a representative unit cell. The volume of fiber in the entire representative unit cell can then be found by using the tow fiber volume fraction. Taking the volume average of the fiber over the representative unit cell gives the overall fiber volume fraction of the laminate. The geometric parameters are summarized in Table 2 .

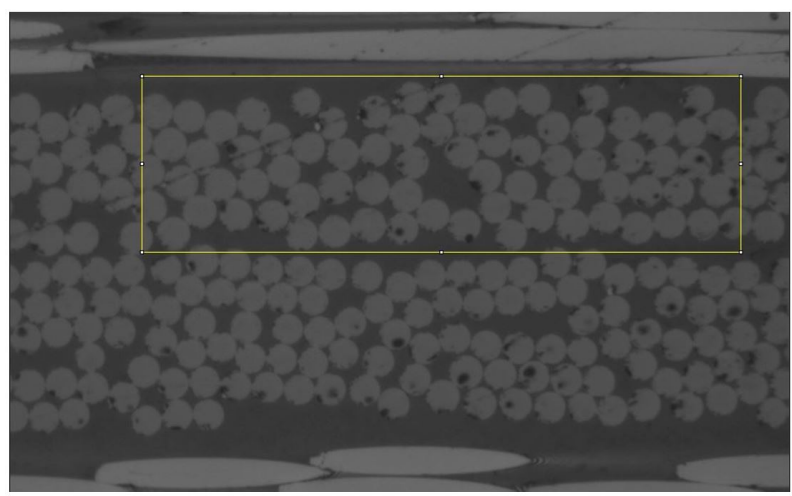

Fig. 5 Cross section of a tow. 
Table 2 Geometric properties of the cured M30S/PMT-F7 composites.

\begin{tabular}{lcc}
\hline \hline Geometric Properties & 3-Ply & 4-Ply \\
\hline Weave length & $6.674 \mathrm{~mm}$ & $6.674 \mathrm{~mm}$ \\
Laminate thickness & $0.171 \mathrm{~mm}$ & $0.228 \mathrm{~mm}$ \\
Maximum tow thickness & $0.0286 \mathrm{~mm}$ & $0.0286 \mathrm{~mm}$ \\
Tow width & $3.164 \mathrm{~mm}$ & $3.164 \mathrm{~mm}$ \\
Tow area & $0.0802 \mathrm{~mm}^{2}$ & $0.0802 \mathrm{~mm}^{2}$ \\
Fiber volume fraction of tow & 0.62 & 0.62 \\
Fiber volume fraction of laminate & 0.52 & 0.52 \\
\hline
\end{tabular}

The geometry of the unit cell was modeled in TexGen [16] (Fig. 6), an open source textile modeling software. The waviness of the tows were defined to follow the shape of a spline curve and a constant tow cross section geometry was defined along the spline characterized by a super ellipse [17] in the following form

$$
\begin{aligned}
& x=a \sin \theta \\
& y=b \cos ^{n} \theta
\end{aligned}
$$

where $a$ and $b$ are half the width and height of the super ellipse respectively. The value of $n$ was selected such that the tow cross-sectional area of the model matches that of the actual tows. The polygon shifts from an ellipse to a rectangle as $n$ goes from 1 to 0 . At $n=0.6$ the area of the super ellipse was comparable to the actual cross sectional area of the tow.

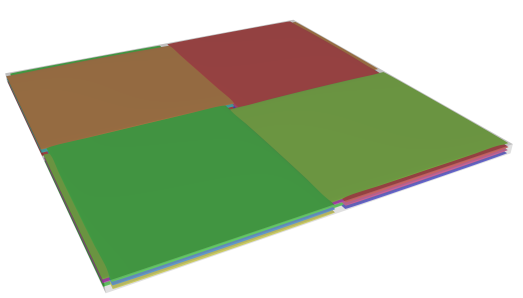

(a)

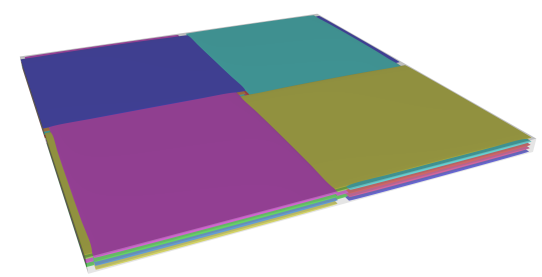

(b)

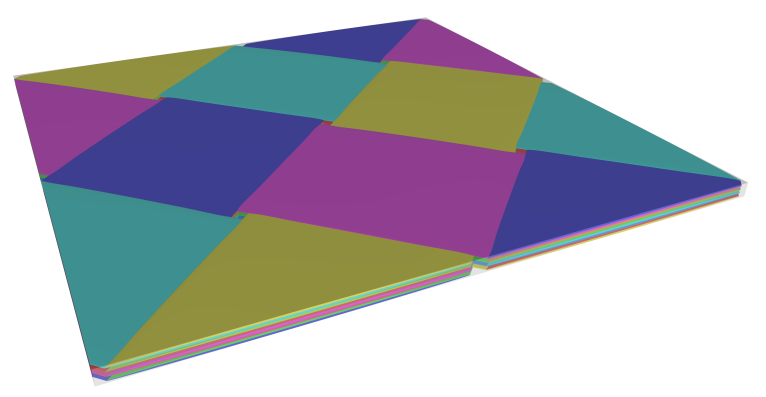

(c)

Fig. 6 Unit cell geometries as modeled in TexGen: a) 3-ply plain weave laminate, b) 4-ply plain weave laminate, and c) 4-ply $\mathbf{4 5}^{\circ}$ rotated laminate.

\section{B. Tow Model}

The epoxy as discussed in Section III intrinsically shows viscoelastic behavior where as the fibers do not manifest such characteristics hence behaving elastically over time. Therefore, this integration of the fibers and matrix within 
the tow gives effect to a combined material property definition which accompanies viscoelastic behavior. Therefore since the tows are modeled as a single continuum in the numerical model the viscoelastic behavior of the tows has to be characterized. The tows fundamentally can be considered as an assembly with unidirectional fiber embedded in a matrix. The behavior of this system can be described by a model formulated with a single fiber surrounded by matrix as shown in Fig. 7 This implies the assumption of a square arrangement of fibers within the tows.

The model is essentially a cube with dimensions dictated by the tow volume fraction and the fiber diameter. Furthermore, the material behavior of the model is transversely isotropic in the 2-3 plane. The length of the cube is $L=6.19 \mu \mathrm{m}$ which was calculated to comply with the tow volume fraction of 0.62 . The analysis was performed by using Abaqus [18] finite element package. Six reference points were located next to each surface on the exterior of the unit cell and the degrees of freedom of the nodes on the surface of the each side of the cube were constrained to the respective reference point. The three reference points $X 1, Y 1$ and $Z 1$ are connected to the three surfaces as shown in Fig. 7, and the reference points $X 2, Y 2, Z 2$ are located on respective opposite faces of the unit cell. The model was meshed with linear tetrahedral elements.

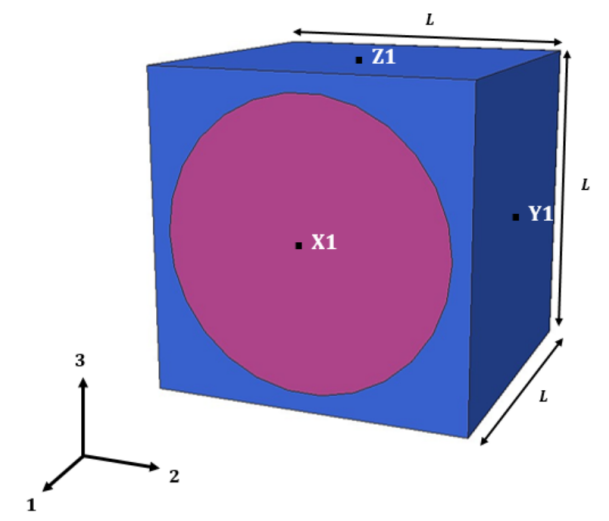

Fig. 7 Unit cell of a unidirectional tow.

The constitutive relationship which describes the material model of the unidirectional tow is given by Eq.(1) and $C$ is the relaxation modulus tensor of the tow which contains the parameters that are required to be deduced from the numerical analysis of the unidirectional tow model and has the form

$$
C=\left[\begin{array}{cccccc}
C_{11} & C_{12} & C_{13} & 0 & 0 & 0 \\
C_{12} & C_{22} & C_{23} & 0 & 0 & 0 \\
C_{13} & C_{23} & C_{22} & 0 & 0 & 0 \\
0 & 0 & 0 & C_{44} & 0 & 0 \\
0 & 0 & 0 & 0 & C_{55} & 0 \\
0 & 0 & 0 & 0 & 0 & C_{55}
\end{array}\right]
$$

where $C_{44}$ can be calculated by $C_{22}$ and $C_{23}$ which is facilitated from transverse isotropy as

$$
C_{44}=\frac{C_{22}-C_{23}}{2}
$$

The five independent coefficients $C_{11}, C_{12}, C_{22}, C_{23}$ and $C_{55}$ can be found by carrying out three different simulations. For example, to find $C_{11}$ a $0.1 \%$ strain was given to the unit cell in the 1-direction setting all other strains to zero. The simulation was carried out in two time steps, the first being 1 second, was used to impose the strain on the model and the second step holds the strain applied in the first step for a time period of $10^{14}$ seconds. The stress relaxation of $\sigma_{1}(t)$ was found over time for the unit cell to calculate $C_{11}$. The data obtained over the period of time was fit into a Prony series as defined in Eq.(2). The relaxation times $\left(\rho_{k}\right)$ of the Prony Series were set to be as same as that of the epoxy PMT-F7. 


\section{Laminate Model}

The laminate was treated as a viscoelastic Kirchhoff plate and the relaxation ABD matrix that describes the material model of the laminate can be found by the homogenization carried out for the laminate unit cell model. The matrix surrounding the tows was defined as an isotropic viscoelastic material and the tows were defined by the material model as formulated in Sec IV.B. The representative unit cell formulated in TexGen is meshed with tetrahedral linear elements and exported to Abaqus for numerical analysis. The model for the 3-ply plain weave laminate is shown in Fig. 8 . The 4-ply plain weave at $0^{\circ}$ and $45^{\circ}$ were set up in an identical way.

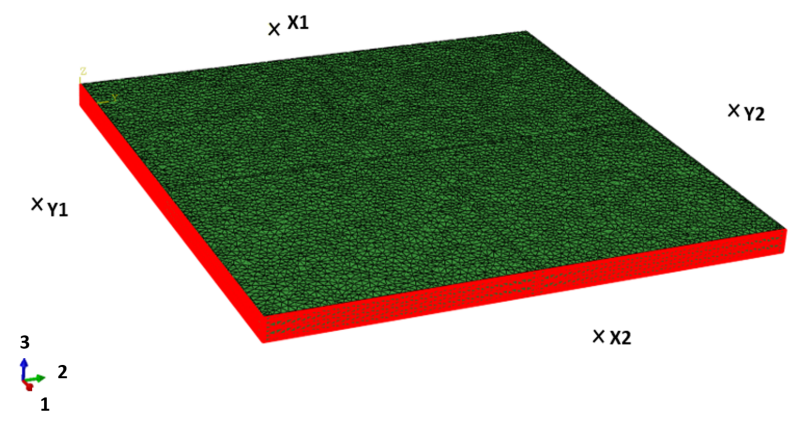

Fig. 8 Finite element mesh of 3-ply laminate.

Four reference points (X1, X2, Y1, Y2) located on the periphery of the unit cell are constrained to the plate surfaces by means of coupling constrains in ABAQUS. The goal is to find the ABD relaxation matrix (Eqs. 10 12) that describes the properties of the composite. The periodicity of the unit cell is assured by applying periodic boundary conditions to the reference points. The constraints for relative translations and rotations of the opposite reference points of the assumed viscoelastic Kirchhoff plate can be defined as

$$
\begin{aligned}
& \Delta u_{1}^{1}=\epsilon_{1} \Delta L \\
& \Delta u_{2}^{1}=\frac{1}{2} \epsilon_{3} \Delta L \\
& \Delta u_{3}^{1}=-\frac{1}{2} \kappa_{3} x_{2} \Delta L \\
& \Delta \theta_{1}^{1}=-\frac{1}{2} \kappa_{3} \Delta L \\
& \Delta \theta_{2}^{1}=\kappa_{1} \Delta L \\
& \Delta \theta_{3}^{1}=0 \\
& \Delta u_{1}^{2}=\frac{1}{2} \epsilon_{3} \Delta L \\
& \Delta u_{2}^{2}=\epsilon_{2} \Delta L
\end{aligned}
$$




$$
\begin{aligned}
& \Delta u_{3}^{2}=-\frac{1}{2} \kappa_{3} x_{1} \Delta L \\
& \Delta \theta_{2}^{2}=\frac{1}{2} \kappa_{3} \Delta L \\
& \Delta \theta_{1}^{2}=-\kappa_{2} \Delta L \\
& \Delta \theta_{3}^{2}=0
\end{aligned}
$$

where $u$ and $\theta$ are translations and rotations of the reference points and subscripts in $u$ denote the direction and the subscripts in $\theta$ denote the axis of rotation. The superscripts represent the direction of the connecting nodes in the opposite faces and $\Delta L$ is the distance between the opposite faces of the plate model. Translations and rotations are applied to the boundary reference points to impose the desired mid-plane strains and out-of-plane curvatures. The methodology to calculate the entries of the ABD matrix is similar to that followed in Sec IV.B.

\section{Results}

\section{A. Elastic Behavior}

For the 3-ply plain weave laminate, non-linear geometric simulations in the elastic domain were carried out to obtain the ABD stiffness matrix. A two step homogenization was followed for this analysis, first to find the engineering constants of the unidirectional fiber composite, in other words the tows and the second step to incorporate these engineering constants in Kirchhoff elastic plate model. The engineering constants acquired from the unidirectional tow model are presented in Table 3 .

Table 3 Properties of cured M30S/PMT-F7 tow.

\begin{tabular}{lc}
\hline \hline Tow Properties & M30S/PMT-F7 \\
\hline Longitudinal Stiffness, $E_{1}(\mathrm{MPa})$ & 183500 \\
Transverse Stiffness, $E_{2}=E_{3}(\mathrm{MPa})$ & 9064 \\
Shear Stiffness, $G_{12}=G_{13}(\mathrm{MPa})$ & 5941 \\
In-plane Shear Stiffness, $G_{23}(\mathrm{MPa})$ & 3106 \\
Poisson's ratio, $v_{12}=v_{13}$ & 0.28 \\
Poisson's ratio, $v_{23}$ & 0.4 \\
\hline
\end{tabular}

The ABD matrix obtained for the plain weave composite is

$$
A B D=\left[\begin{array}{cccccc}
11900 & 467 & 0 & 0 & 2 & -1 \\
467 & 11900 & 0 & 0 & 21 & 5 \\
0 & 0 & 745 & -1 & 0 & 0 \\
-3 & 1 & 0 & 28 & 1 & -10 \\
1 & 41 & 0 & 1 & 28 & -10 \\
10 & -10 & 4 & 0 & 0 & 16
\end{array}\right]
$$

Here the $A$ matrix was obtained in the expected form without any coupling between axial and shear components. The $B$ matrix which relates the in-plane loads to curvatures and the moments to in-plane strains, shows non-zero values and fails to retain symmetry of the matrix. It was noted that these values become prominent when carrying out a non-linear geometric analysis on the unit cell model as opposed to having insignificant values in the linear geometric case. The $D$ matrix does not show symmetry as well. These need to be further investigated in the elastic characterization. 
Simulations for bending were carried out for high curvatures and the output was compared against the experimental results obtained from bending tests that were performed on the 3-ply laminate, using the Column Bending Test method [1]. The results are illustrated in Fig. 9. The numerical analysis was carried out again by using quadratic elements in place of linear elements and similar results were obtained. A linear moment curvature response was obtained for both numerical simulation and testing. Here, there is a 3.5\% difference in the bending stiffness between the values acquired from numerical analysis and testing. One reason for this discrepancy can be that, when constructing the representative volume element, the plies in-phase configuration is assumed even though in reality the types of configurations can be of a wide range.

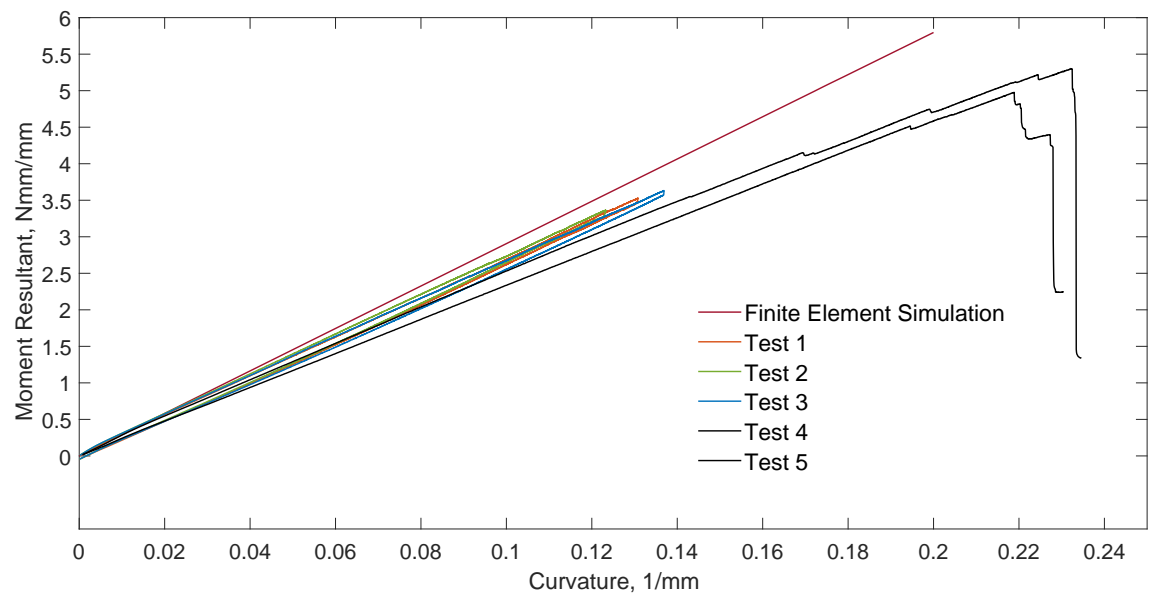

Fig. 9 The moment curvature response for the 3-ply plain weave laminate.

\section{B. Viscoelastic Behavior}

For the 4-ply plain weave laminate, viscoelastic analysis was carried out for both $0^{\circ}$ and $45^{\circ}$ cases. Each term in the relaxation modulus tensor for the unidirectional tow model was formulated in the form of a Prony series by obtaining the relaxation data from the numerical analysis and performing a non-linear curve fit using the least squares method in Matlab [19]. The entries in the relaxation modulus tensor $C$ obtained from this method are plotted in Fig. 10.

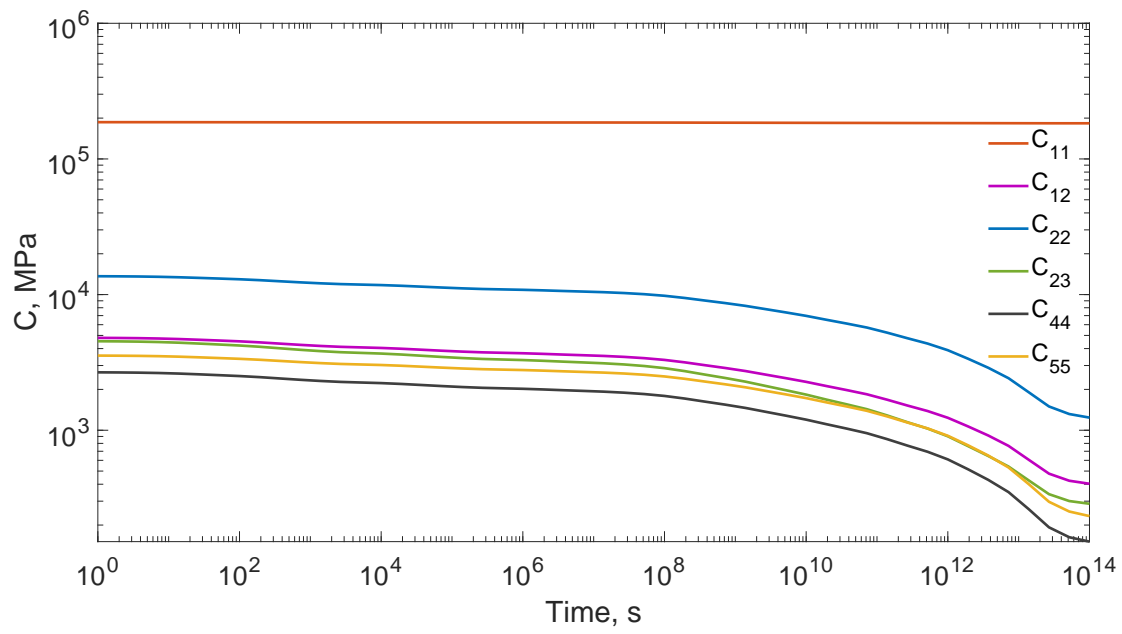

Fig. 10 Tow relaxation moduli. 
Note that the time dependence of $C_{11}$ is insignificant since the fibers are dominant in the 1-direction where the elastic behavior is prominent. The Prony series coefficients are given in Appendix Table A.2.

Non-linear geometric analyses were performed on the 4-ply unit cell $\left(0^{\circ}\right)$ for stretching and linear geometric analysis was performed for bending. Again the Prony coefficients for the ABD relaxation matrix were found from the relaxation data by using the non-linear curve fitting in Matlab. The Prony series are plotted in Fig. 11 and Fig. 12 and the Prony coefficients are given in Appendix Table A.3.

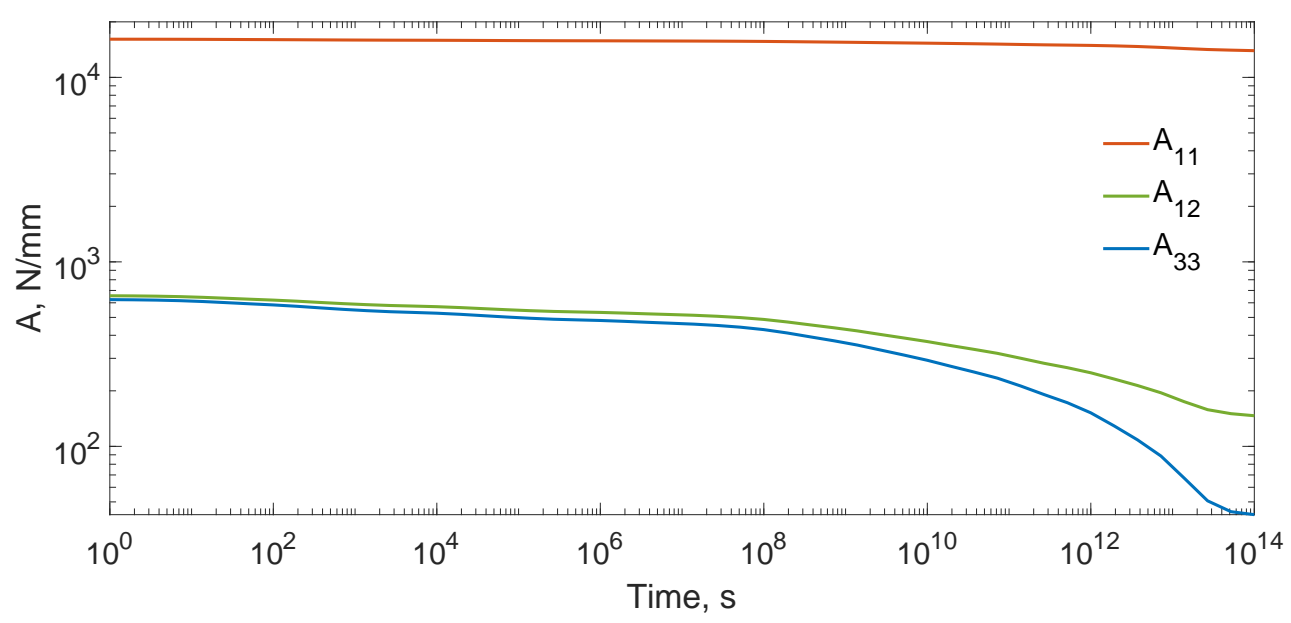

Fig. 11 In-plane relaxation coefficients of 4-ply lamina.

Again $A_{11}$ shows little relaxation since there are fibers dominating the behavior in 1-direction. The coupling coefficient $A_{12}$ shows considerable relaxation. The same behavior can be seen from $A_{33}$ which is the shear relaxation stiffness with even more relaxation towards the end of the time span considered.

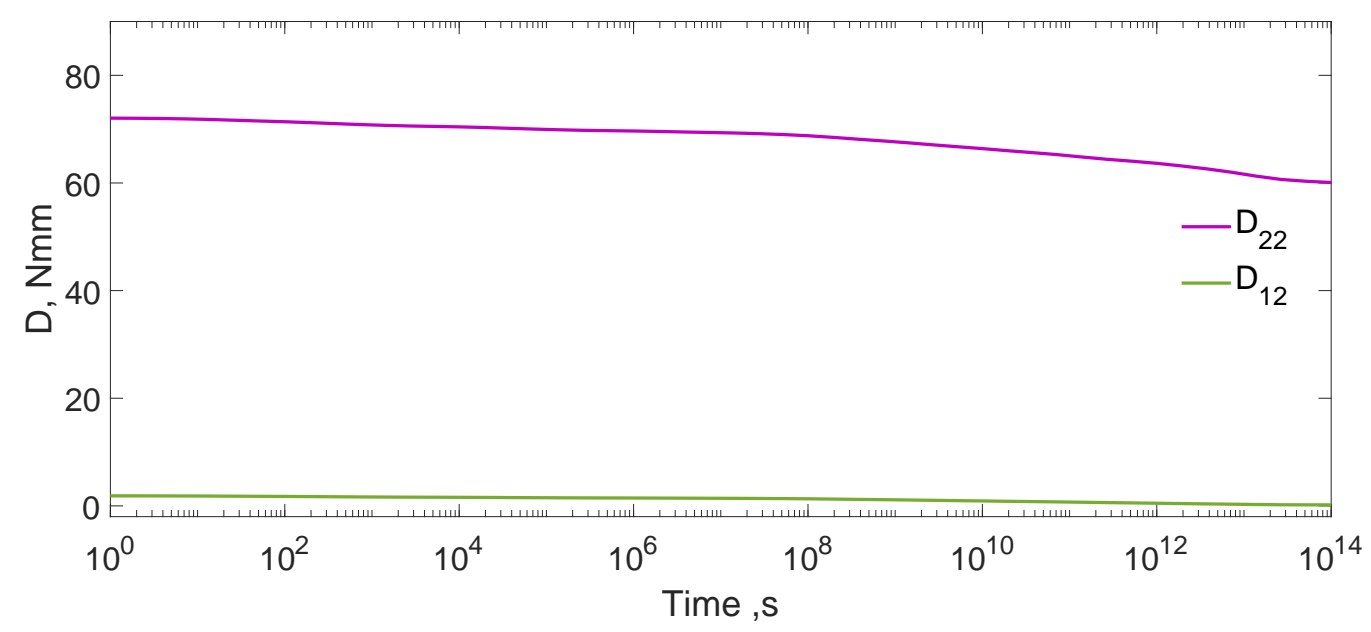

Fig. 12 Out-of-plane relaxation coefficients of 4-ply lamina.

Bending stiffness $D_{22}$ has a considerable $18 \%$ reduction in value, in the time span considered. In applications of deployable booms, this would mean that the moment causing the self deploying effect reduces during long-term stowage which needs to be addressed when designing the structures.

Numerical analysis for the unit cell for the 4-ply lamina rotated by $45^{\circ}$ was performed in a similar manner and the 
Prony series for the terms in ABD relaxation matrix are plotted in Fig. 13 and Fig. 14 and the Prony coefficients are given in Appendix Table A.4

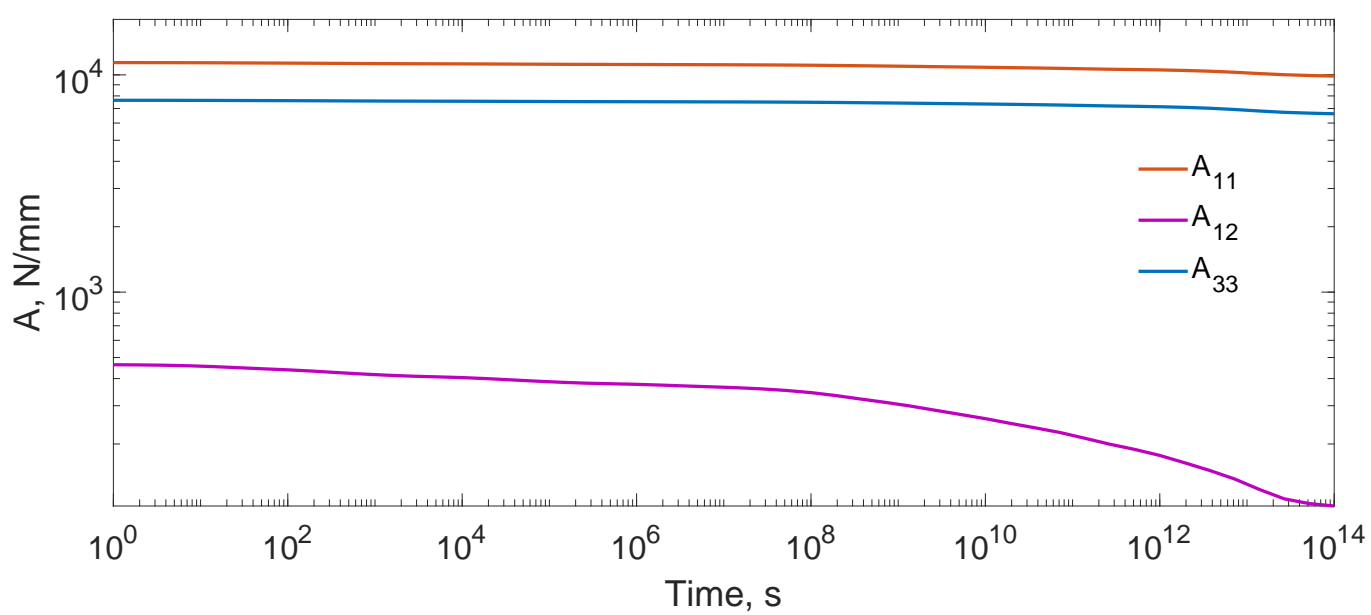

Fig. 13 In-plane relaxation coefficients of $45^{\circ}$ rotated four-ply laminate.

The $A_{11}$ here follows a similar behavior to that of $0^{\circ}$ case with small relaxation, but numerically less in value since the stiffness is dependent on fibers oriented at a $45^{\circ}$ angle. In contrast to the previous case, $A_{12}$ exhibits significant relaxation and $A_{33}$ shows insignificant relaxation overtime.

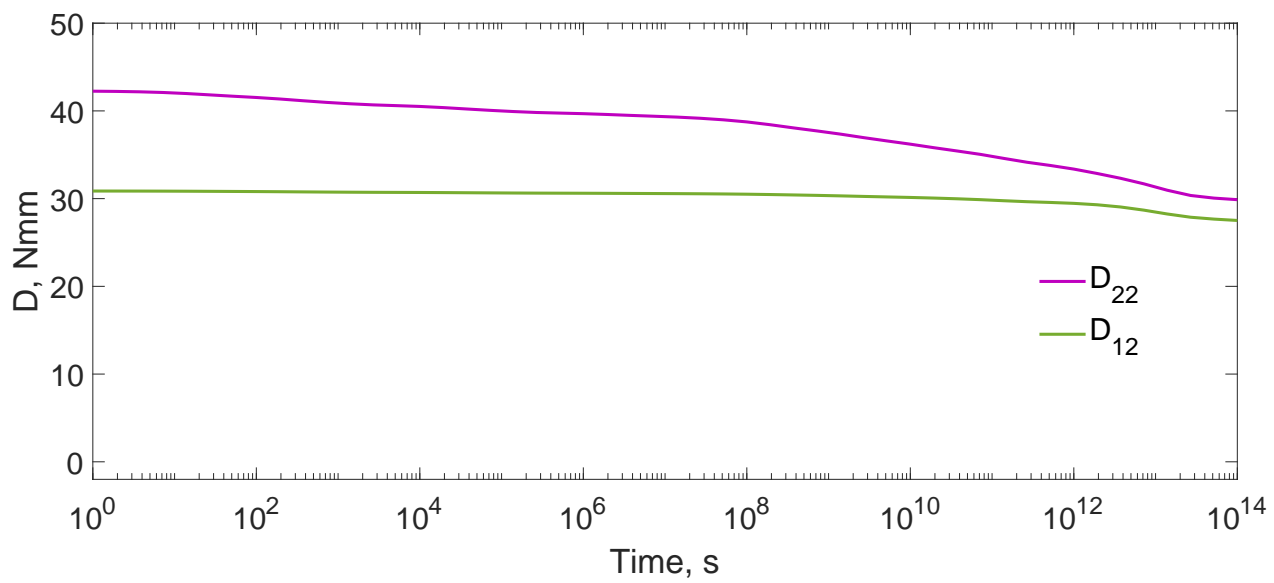

Fig. 14 Out-of-plane relaxation coefficients of $45^{\circ}$ rotated 4-ply laminate.

The reduction in bending stiffness $D_{22}$ is a significant $38 \%$ in the time span considered and the stiffness is much lower compared to the $0^{\circ}$ case but the coupling term is much higher.

The distribution of stresses in the 1-direction for bending are illustrated in Fig. 15 and Fig. 16 for two moments in time, first one at $\mathrm{t}=0 \mathrm{~s}$ which is the start of the second step and the other one is at $\mathrm{t}=10^{14} \mathrm{~s}$. The relaxation of stress can be observed from the stress plots at the, two different moments in time. 


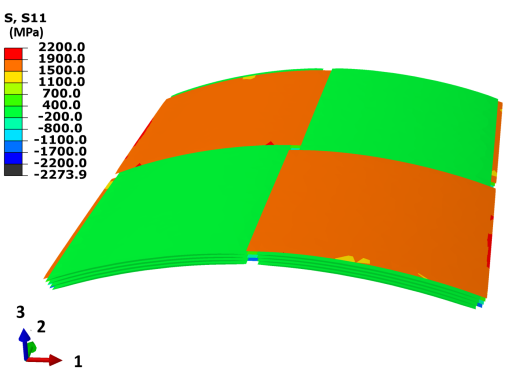

(a)

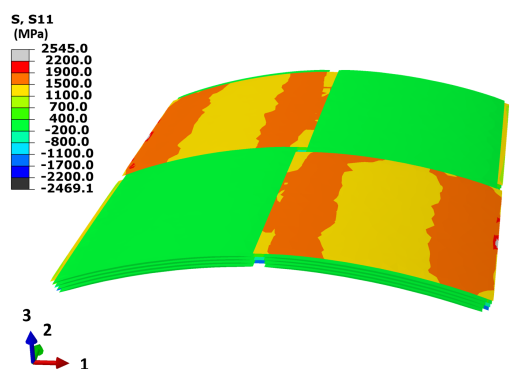

(b)

Fig. 15 Bending of 4-ply laminate oriented at $0^{\circ}$ : a) Stress distribution in 1-direction at $t=0 \mathrm{~s}$, and $\mathrm{b}$ ) Stress distribution in 1-direction at $\mathrm{t}=10^{14} \mathrm{~s}$.

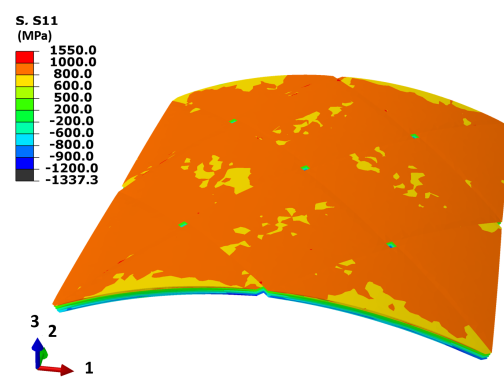

(a)

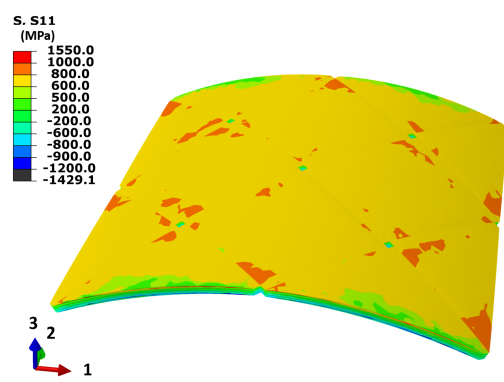

(b)

Fig. 16 Bending of 4-ply laminate oriented at $45^{\circ}$ : a) Stress distribution in 1-direction at $t=0 \mathrm{~s}$, and b) Stress distribution in 1-direction at $\mathrm{t}=10^{14} \mathrm{~s}$.

\section{Conclusion}

The thin-ply composites have become a crucial component in light weight deployable structures over the years. The structure of a thin composite, in a material point of view is a complex assembly which has caught a lot of interest among researchers. The integration of two different materials one being the epoxy with viscoelastic material properties and the fiber showing only elastic behavior has a combined effect on the structure. Furthermore, the tows been woven in different directions raises more questions as to how the overall stiffness of the laminates vary as studied in different orientations. So a model has been formulated to study the elastic behaviors, viscoelastic behaviors as well as the effect of orientation of thin ply laminates.

A two scale homogenization was adapted, first one to build the material model of unidirectional lamina which describes the behavior of the tows. This was performed for both the elastic and viscoelastic behavior considering isotropy in the transverse direction. Elastic model of the tows incorporated with the woven fiber plate model was used to assess the bending behavior of the 3-ply laminate at high curvatures and it can be concluded that in there was no variation in bending stiffness as the curvature was increased. The same observation was made with the experiments.

The viscoelastic properties of the epoxy was integrated into the unidirectional tow model to obtain the viscoelastic characterization of the tows. Since the fiber behavior dominates the behavior of the tows in the longitudinal direction, $C_{11}$ of relaxation modulus tensor was observed to have very small relaxation over time. Since the other terms describing the properties in the transverse direction and shear has the involvement of the matrix to a considerable amount, they show relaxation over time. This model was used to describe the viscoelastic tow of the laminate model and obtain the relaxation ABD matrix. Analyses were carried out for the 4-ply plain weave laminate for two different orientations $0^{\circ}$ and $45^{\circ}$. The ABD relaxation matrix was formulated for both the scenarios. The coefficients relating to twist are yet to be performed on the laminate models. The future work will continue in performing relaxation tests on the laminates in 
the study and the numerical model will be validated and optimized in comparison with test results.

\section{A. Appendix}

Table A.1 Relaxation times and Prony coefficients of PMT-F7.

\begin{tabular}{ccc}
\hline \hline$i$ & $\rho_{k}[\mathrm{~s}]$ & $E_{i}[\mathrm{MPa}]$ \\
\hline$\infty$ & - & 149.5 \\
1 & $1.89 \mathrm{E}+01$ & 74.75 \\
2 & $1.00 \mathrm{E}+02$ & 194.35 \\
3 & $1.00 \mathrm{E}+03$ & 254.15 \\
4 & $2.00 \mathrm{E}+04$ & 110.63 \\
5 & $1.00 \mathrm{E}+05$ & 158.47 \\
6 & $1.95 \mathrm{E}+06$ & 92.69 \\
7 & $1.77 \mathrm{E}+07$ & 71.76 \\
8 & $1.74 \mathrm{E}+08$ & 299 \\
9 & $1.38 \mathrm{E}+09$ & 299 \\
10 & $1.00 \mathrm{E}+10$ & 299 \\
11 & $1.00 \mathrm{E}+11$ & 299 \\
12 & $1.00 \mathrm{E}+12$ & 299 \\
13 & $1.00 \mathrm{E}+13$ & 299 \\
14 & $1.00 \mathrm{E}+14$ & 89.7 \\
\hline
\end{tabular}

Table A.2 Relaxation times and Prony coefficients of unidirectional tow model.

\begin{tabular}{cccccccc}
\hline \hline$k$ & $\rho_{k}$ & $C_{11, k}$ & $C_{21, k}$ & $C_{22, k}$ & $C_{23, k}$ & $C_{44, k}$ & $C_{55, k}$ \\
\hline$\infty$ & - & 183114.7 & 374.9 & 1131.8 & 269.4 & 135.3 & 207.2 \\
1 & $1.89 \mathrm{E}+01$ & 142.3 & 163.8 & 406.8 & 188.8 & 98.6 & 113.5 \\
2 & $1.00 \mathrm{E}+02$ & 209.0 & 241.5 & 600.8 & 277.2 & 140.0 & 161.8 \\
3 & $1.00 \mathrm{E}+03$ & 232.7 & 274.8 & 705.6 & 306.9 & 163.8 & 195.6 \\
4 & $2.00 \mathrm{E}+04$ & 138.0 & 163.2 & 414.1 & 180.5 & 95.6 & 114.0 \\
5 & $1.00 \mathrm{E}+05$ & 173.1 & 206.2 & 544.7 & 228.4 & 122.2 & 148.9 \\
6 & $1.95 \mathrm{E}+06$ & 113.9 & 137.1 & 356.5 & 146.2 & 79.7 & 97.9 \\
7 & $1.77 \mathrm{E}+07$ & 80.2 & 95.9 & 248.6 & 105.3 & 56.5 & 68.6 \\
8 & $1.74 \mathrm{E}+08$ & 355.8 & 429.8 & 1143.9 & 460.2 & 251.4 & 312.4 \\
9 & $1.38 \mathrm{E}+09$ & 373.0 & 461.3 & 1262.1 & 469.5 & 266.9 & 343.0 \\
10 & $1.00 \mathrm{E}+10$ & 383.6 & 482.0 & 1370.9 & 471.0 & 276.7 & 368.8 \\
11 & $1.00 \mathrm{E}+11$ & 412.3 & 527.2 & 1533.9 & 474.6 & 297.9 & 407.9 \\
12 & $1.00 \mathrm{E}+12$ & 398.0 & 515.1 & 1586.2 & 452.2 & 291.9 & 415.8 \\
13 & $1.00 \mathrm{E}+13$ & 495.3 & 657.6 & 2084.7 & 462.9 & 358.8 & 532.0 \\
14 & $1.00 \mathrm{E}+14$ & 56.1 & 76.7 & 290.8 & 48.1 & 42.6 & 69.6 \\
\hline
\end{tabular}


Table A.3 Relaxation times and Prony coefficients of $0^{\circ}$ 4-ply laminate.

\begin{tabular}{ccccccc}
\hline \hline$k$ & $\rho_{k}$ & $A_{11, k}$ & $A_{12, k}$ & $A_{33, k}$ & $D_{11, k}$ & $D_{12, k}$ \\
\hline$\infty$ & - & 13813.33 & 141.15 & 40.81 & 59.75 & 0.18 \\
1 & $1.89 \mathrm{E}+01$ & 58.73 & 23.05 & 26.52 & $4.44 \mathrm{E}-01$ & $7.32 \mathrm{E}-02$ \\
2 & $1.00 \mathrm{E}+02$ & 67.70 & 26.52 & 31.13 & $5.11 \mathrm{E}-01$ & $8.74 \mathrm{E}-02$ \\
3 & $1.00 \mathrm{E}+03$ & 67.08 & 25.35 & 29.92 & $4.98 \mathrm{E}-01$ & $8.43 \mathrm{E}-02$ \\
4 & $2.00 \mathrm{E}+04$ & 50.51 & 19.47 & 22.20 & $3.71 \mathrm{E}-01$ & $6.29 \mathrm{E}-02$ \\
5 & $1.00 \mathrm{E}+05$ & 61.04 & 22.71 & 26.71 & $4.50 \mathrm{E}-01$ & $7.50 \mathrm{E}-02$ \\
6 & $1.95 \mathrm{E}+06$ & 40.56 & 15.52 & 17.84 & $3.00 \mathrm{E}-01$ & $5.12 \mathrm{E}-02$ \\
7 & $1.77 \mathrm{E}+07$ & 30.66 & 10.79 & 12.55 & $2.16 \mathrm{E}-01$ & $3.55 \mathrm{E}-02$ \\
8 & $1.74 \mathrm{E}+08$ & 126.69 & 48.48 & 56.50 & $9.49 \mathrm{E}-01$ & $1.61 \mathrm{E}-01$ \\
9 & $1.38 \mathrm{E}+09$ & 162.71 & 53.41 & 61.27 & $1.09 \mathrm{E}+00$ & $1.78 \mathrm{E}-01$ \\
10 & $1.00 \mathrm{E}+10$ & 142.36 & 54.75 & 64.74 & $1.11 \mathrm{E}+00$ & $1.90 \mathrm{E}-01$ \\
11 & $1.00 \mathrm{E}+11$ & 266.38 & 63.84 & 71.64 & $1.49 \mathrm{E}+00$ & $2.18 \mathrm{E}-01$ \\
12 & $1.00 \mathrm{E}+12$ & 89.68 & 53.84 & 70.34 & $1.12 \mathrm{E}+00$ & $2.13 \mathrm{E}-01$ \\
13 & $1.00 \mathrm{E}+13$ & 742.11 & 82.84 & 88.78 & $2.84 \mathrm{E}+00$ & $2.44 \mathrm{E}-01$ \\
14 & $1.00 \mathrm{E}+14$ & 389.43 & 14.71 & 4.94 & $9.28 \mathrm{E}-01$ & $1.47 \mathrm{E}-02$ \\
\hline
\end{tabular}

Table A.4 Relaxation times and Prony coefficients of $45^{\circ}$ rotated 4-ply laminate.

\begin{tabular}{ccccccc}
\hline \hline$k$ & $\rho_{k}$ & $A_{11, k}$ & $A_{12, k}$ & $A_{33, k}$ & $D_{11, k}$ & $D_{12, k}$ \\
\hline$\infty$ & - & 9767.50 & 99.81 & 6552.30 & 29.62 & 27.28 \\
1 & $1.89 \mathrm{E}+01$ & 41.53 & 16.30 & 19.70 & $4.79 \mathrm{E}-01$ & $3.57 \mathrm{E}-02$ \\
2 & $1.00 \mathrm{E}+02$ & 47.87 & 18.76 & 23.45 & $5.45 \mathrm{E}-01$ & $5.42 \mathrm{E}-02$ \\
3 & $1.00 \mathrm{E}+03$ & 47.43 & 17.92 & 24.66 & $5.37 \mathrm{E}-01$ & $5.59 \mathrm{E}-02$ \\
4 & $2.00 \mathrm{E}+04$ & 35.72 & 13.77 & 17.45 & $3.99 \mathrm{E}-01$ & $3.87 \mathrm{E}-02$ \\
5 & $1.00 \mathrm{E}+05$ & 43.16 & 16.06 & 22.78 & $4.81 \mathrm{E}-01$ & $5.32 \mathrm{E}-02$ \\
6 & $1.95 \mathrm{E}+06$ & 28.68 & 10.98 & 14.77 & $3.22 \mathrm{E}-01$ & $3.45 \mathrm{E}-02$ \\
7 & $1.77 \mathrm{E}+07$ & 21.68 & 7.63 & 11.42 & $2.30 \mathrm{E}-01$ & $2.88 \mathrm{E}-02$ \\
8 & $1.74 \mathrm{E}+08$ & 89.58 & 34.28 & 47.01 & $1.01 \mathrm{E}+00$ & $1.08 \mathrm{E}-01$ \\
9 & $1.38 \mathrm{E}+09$ & 115.05 & 37.76 & 65.32 & $1.16 \mathrm{E}+00$ & $1.86 \mathrm{E}-01$ \\
10 & $1.00 \mathrm{E}+10$ & 100.66 & 38.71 & 59.37 & $1.17 \mathrm{E}+00$ & $1.47 \mathrm{E}-01$ \\
11 & $1.00 \mathrm{E}+11$ & 188.36 & 45.14 & 123.40 & $1.54 \mathrm{E}+00$ & $4.36 \mathrm{E}-01$ \\
12 & $1.00 \mathrm{E}+12$ & 63.42 & 38.07 & 53.90 & $1.18 \mathrm{E}+00$ & $9.79 \mathrm{E}-02$ \\
13 & $1.00 \mathrm{E}+13$ & 524.75 & 58.58 & 417.85 & $2.88 \mathrm{E}+00$ & $1.68 \mathrm{E}+00$ \\
14 & $1.00 \mathrm{E}+14$ & 275.37 & 10.41 & 185.71 & $7.12 \mathrm{E}-01$ & $6.37 \mathrm{E}-01$ \\
\hline
\end{tabular}

Acknowledgments

The authors would like thank the NASA Langley Research Center for their financial support through the award 80NSSC18M0015. 


\section{References}

[1] Fernandez, J. M., and Murphey, T. W., "A Simple Test Method for Large Deformation Bending of Thin High Strain Composite Flexures," 2018 AIAA Spacecraft Structures Conference, 2018, p. 0942.

[2] Sihn, S., Kim, R. Y., Kawabe, K., and Tsai, S. W., "Experimental studies of thin-ply laminated composites," Composites Science and Technology, Vol. 67, No. 6, 2007, pp. 996-1008.

[3] Soykasap, O., Watt, A., and Pellegrino, S., "New Deployable Reflector Concept," 45th AIAA/ASME/ASCE/AHS/ASC Structures, Structural Dynamics and Materials Conference, 2004.

[4] Tze Tan, L., and Pellegrino, S., "Stiffness Design of Spring Back Reflectors," 46th AIAA/ASME/ASCE/AHS/ASC Structures, Structural Dynamics and Materials Conference, Vol. 4, 2002.

[5] Datashvili, L., Baier, H., Schimitschek, J., Lang, M., and Huber, M., "High precision large deployable space reflector based on pillow-effect-free technology," 48th AIAA/ASME/ASCE/AHS/ASC Structures, Structural Dynamics, and Materials Conference, 2007, p. 2186.

[6] Block, J., Straubel, M., and Wiedemann, M., "Ultralight deployable booms for solar sails and other large gossamer structures in space,” Acta Astronautica, Vol. 68, No. 7-8, 2011, pp. 984-992.

[7] Mobrem, M., and Adams, D., "Deployment analysis of the lenticular jointed antennas onboard the mars express spacecraft," Journal of Spacecraft and Rockets, Vol. 46, No. 2, 2009, pp. 394-402.

[8] Fernandez, J. M., Rose, G., Stohlman, O. R., Younger, C. J., Dean, G. D., Warren, J. E., Kang, J. H., Bryant, R. G., and Wilkie, K. W., "An Advanced Composites-Based Solar Sail System for Interplanetary Small Satellite Missions," 2018 AIAA Spacecraft Structures Conference, 2018, p. 1437.

[9] Soykasap, O., "Micromechanical models for bending behavior of woven composites," Journal of Spacecraft and Rockets, Vol. 43, No. 5, 2006, pp. 1093-1100.

[10] Gomez-Delrio, A., and Kwok, K., "Viscoelastic Behavior of Thin-Ply Composites for Deployable Structures," $69^{\text {th }}$ International Astronautical Congress (IAC), 2018.

[11] Mallikarachchi, H., "Thin-walled Composite Deployable Booms with Tape-Spring Hinges," Ph.D. thesis, University of Cambridge, May 2011.

[12] Kwok, K., and Pellegrino, S., "Micromechanics models for viscoelastic plain-weave composite tape springs," AIAA Journal, Vol. 55, No. 1, 2016, pp. 309-321.

[13] TORAY industries, “TORAYCA yarn,”, 2018. URLhttp://www.torayca.com/en/lineup/product/pro_001_01.html

[14] Borowski, E. C., "Viscoelastic Effects in Carbon Fiber Reinforced Polymer Strain Energy Deployable Composite Tape Springs," Ph.D. thesis, University of New Mexico, 7 2017. URL https://digitalrepository.unm.edu/ce_etds/174.

[15] W.S., R., "ImageJ,", 1997-2018. URLhttps://imagej.nih.gov/ij/.

[16] Brown, L. P., and Sherburn, M., “TexGen,”, 2017, December 13. URL http://doi.org/10.5281/zenodo.1115604

[17] Sherburn, M., “Geometric and mechanical modelling of textiles," Ph.D. thesis, University of Nottingham, 2007.

[18] Systeme, D., “ABAQUS/Standard,ver.2017,”, 2017.

[19] MathWorks, “MATLAB,”, R2017a. 